\title{
MECANISMOS ADEQUADOS DE SOLUÇÃO DE CONFLITOS COMO POLÍTICA PÚBLICA PARA A EFETIVAÇÃO DO ACESSO À JUSTIÇA
}

\author{
ADEQUATE CONFLICT SOLUTION MECHANISMS AS PUBLIC POLICIE FOR \\ THE EFFECTIVENESS OF ACCESS TO JUSTICE
}

\author{
MECANISMOS ADECUADOS DE SOLUCIÓN DE CONFLICTOS COMO POLÍTICA \\ PÚBLICA PARA LA EFICACIA DEL ACCESO A LA JUSTICIA
}

\author{
ALEXANDRE WALMOTT BORGES \\ http://orcid.org/0000-0001-8767-5542 / http://lattes.cnpq.br/6465037595208646 / walmott@gmail.com \\ Universidade Estadual Julio de Mesquita Filho - UNESP. \\ São Paulo, SP; Uberlândia, MG, Brasil.
}

\begin{abstract}
MARIANA LIMA MENEGAZ
http://orcid.org/0000-0001-6081-4012 / http://lattes.cnpq.br/3299079550353723 / mariana_menegaz@hotmail.com Universidade Estadual Julio de Mesquita Filho - UNESP.
\end{abstract}

São Paulo, SP, Brasil.

\begin{abstract}
RESUMO
0 presente trabalho tem por objetivo de investigação analisar as políticas públicas de Mediação e Conciliação como meios potenciais para que o direito ao acesso à justiça seja efetivado. 0 acesso à justiça, que é o objeto observado nesta abordagem, está positivado no artigo $5^{\circ}, \mathrm{XXXV}$, da CF/1988 e é uma garantia constitucional que abrange não apenas a via judicial, mas também as vias extrajudiciais. Nesse sentido, políticas públicas devem ser adotadas para que Mecanismos consensuais possam ser utilizados e assim, as partes se empoderem e dialoguem para solucionar seus conflitos. Na abordagem do artigo é utilizado como referencial o Sistema de Multiportas, em que há utilização da via extrajudicial, a despeito de que algumas demandas tenham por meio mais adequado o processo judicial. Assim, cada controvérsia deve ser analisada individualmente para identificar a sua natureza e qual o Mecanismo mais adequado para sua resolução. A legislação brasileira recentemente positivou os Métodos consensuais, com destaque para a Lei $n^{\circ}$ 13.140/15, o Código de Processo Civil de 2015 e a Resolução n 125/2010, do Conselho Nacional de Justiça. Para tanto, o método utilizado nesta pesquisa é o de contextualização geral inicial, a partir de pesquisa bibliográfica sobre os Mecanismos consensuais, principalmente sobre a Mediação e a Conciliação, bem como sobre o acesso à justiça, que é entendido como acesso à ordem justa. Além do referencial bibliográfico, houve a contextualização no referencial normativo positivado. Passos posteriores são analisadas as possibilidades de utilização destes Mecanismos de solução conflitual e os meios de sua utilização.
\end{abstract}

Palavras-chave: Acesso à justiça; Conciliação; Constituição Federal de 1988; Mediação; Métodos Alternativos de Resolução de Conflitos.

\section{ABSTRACT}

The present work has the objective of investigating the public policies of Mediation and Conciliation as potential means for the right to access to justice to be effective. Access to justice, which is the object of this approach, is reflected in Article 5, XXXV of the CF/1988 and is a constitutional guarantee covering not only the judicial process, but also out-of-court procedures. In this sense, public policies must be adopted so that consensual mechanisms can be used and thus, the parties can empower and dialogue to solve their conflicts. In the approach of the article is used as a reference the Multiport System, in which there is use of the out-of-court procedures, in spite of the fact that some demands have the most appropriate judicial process. Thus, each controversy must be analyzed individually to identify 
its nature and which Mechanism is most suitable for its resolution. The Brazilian legislation recently approved the Consensus Methods, with emphasis on Law 13.140/15, the Code of Civil Procedure of 2015 and Resolution no. $125 / 2010$ of the National Council of Justice. To do so, the method used in this research is the initial general contextualization, based on bibliographic research on the Consensual Mechanisms, mainly on Mediation and Conciliation, as well as on access to justice, which is understood as access to the fair order. In addition to the bibliographic reference, there was the contextualization in the normative referential positive. Later steps are analyzed the possibilities of using these conflict resolution Mechanisms and the means of their use.

Keywords: Access to justice; Conciliation; Federal Constitution of 1988; Mediation; Alternative Methods of Conflict Resolution.

\section{RESUMEN}

El presente trabajo tiene por objetivo de investigación analizar las políticas públicas de Mediación y Conciliación como medios potenciales para que el derecho al acceso a la justicia sea efectuado. El acceso a la justicia, que es el objeto observado en este enfoque, está positivado en el artículo 5, XXXV, de la CF/1988 y es una garantía constitucional que abarca no sólo la vía judicial, sino también las vías extrajudiciales. En ese sentido, políticas públicas deben ser adoptadas para que Mecanismos consensuales puedan ser utilizados y así, las partes se empoderen y dialoguen para solucionar sus conflictos. En el abordaje del artículo se utiliza como referencial el Sistema de Multiportas, en que hay utilización de la vía extrajudicial, a pesar de que algunas demandas tengan por medio más adecuado el proceso judicial. Así, cada controversia debe ser analizada individualmente para identificar su naturaleza y cuál es el Mecanismo más adecuado para su resolución. La legislación brasileña recientemente positivó los Métodos consensuados, con destaque para la Ley n 13.140/15, el Código de Proceso Civil de 2015 y la Resolución n 125/2010, del Consejo Nacional de Justicia. Para ello, el método utilizado en esta investigación es el de contextualización general inicial, a partir de la investigación bibliográfica sobre los Mecanismos consensuados, principalmente sobre la Mediación y la Conciliación, así como sobre el acceso a la justicia, que se entiende como acceso al orden justo. Además del referencial bibliográfico, hubo la contextualización en el referencial normativo positivado. Los pasos posteriores se analizan las posibilidades de utilización de estos Mecanismos de solución conflictiva y los medios de su utilización.

Palabras clave: Acceso a la justicia; Conciliación; Constitución Federal de 1988; Mediación; Métodos Alternativos de Resolución de Conflictos.

\section{SUMÁRIO}

INTRODUÇÃO; 1 O DIREITO DE ACESSO À JUSTIÇA; 1.1 Alternativas à crise do Poder Judiciário: Os Mecanismos de Solução de Conflitos; 2 POLÍTICAS PÚBLICAS DE ACESSO À JUSTIÇA; 2.1 Mediação; 2.2 0 papel do Mediador para efetivação das políticas públicas; 2.3 Conciliação; 2.40 Conciliador e sua atuação nas políticas públicas de Mecanismos consensuais; CONCLUSÃO; REFERÊNCIAS.

\section{INTRODUÇÃO}

É natural que as relações humanas sejam permeadas de conflitos, alguns que possuem lapso temporal curto, outros com períodos maiores e que demoram a serem finalizados. A interação entre as pessoas, jeitos diferentes de pensar, de agir e de reagir, aliados à baixa intolerância existente, geram pontos de tensões que se não forem bem resolvidos, resultam em conflitos em grande escala.

Dentre todas as controvérsias existentes, várias são levadas para a apreciação do Poder Judiciário, por entenderem ser um âmbito de proteção aos direitos, em que um terceiro 
imparcial designado para análise da lide, decide sobre as questões dispostas. Nesse sentido, a Constituição Federal de 1988 (CF/88), em seu artigo 5 , XXXV, dispõe que é direito de todo cidadão que qualquer lesão ou ameaça a direito protegido pelo ordenamento jurídico deve ser amparado pode Poder Judiciário.

A Magna Carta de 1988, também chamada de Constituição Cidadã, indica várias alternativas para que as controvérsias sejam solucionadas, como a possibilidade de recorrer ao Poder Judiciário, além da criação das Defensorias Públicas (artigo 134, CF/88), que atuam em prol dos hipossuficientes e dos vulneráveis, inclusive com apoio jurídico a eles. Ademais, há também a garantia de justiça gratuita para aqueles que não possuem condições econômicas para arcar com os custos do processo (artigo $5^{\circ}$, LXXIV, CF/88).

Desse modo, é possível vislumbrar que o ordenamento jurídico concede algumas opções para que o acesso à justiça seja garantido. Entretanto, é notório que há alguns ajustes que devem ser realizados para que esse direito seja efetivo, que ocorra em tempo hábil e que seja adequado para aquela determinada controvérsia. Além disso, deve não apenas garantir o acesso ao Judiciário, mas sim à uma ordem justa, atuando também no âmbito da cidadania.

A cultura do litígio e da produção de sentença em massa está presente na sociedade e é vislumbrada no aumento de processos nos Tribunais, sendo o reflexo de indivíduos que não sabem dialogar com os demais e que fundamentam suas relações no binômio "ganha-perde", que é caracterizado pela predominância de um ganhador, enquanto a outra parte deve perder.

Entretanto, os métodos foram aprimorados para que o acesso à justiça seja assegurado não apenas através do Poder Judiciário, mas também por meio dos Mecanismos consensuais, como a Mediação e a Conciliação.

Assim, o escopo deste trabalho é analisar as políticas públicas no tocante à Mediação e a Conciliação, para que o direito ao acesso à justiça seja preservado e efetivado, consolidando não apenas uma garantia prescrita na Constituição Federal de 1988, mas também realizando uma mudança de cultura, haja vista que a aplicação dos Métodos Adequados de Resolução de Conflitos, em especial a Mediação e Conciliação, retoma a importância do diálogo entre as partes e fomenta o empoderamento das mesmas, para que elas tenham consciência de que estão capacitadas para resolverem seus conflitos.

Partindo desse pressuposto, o trabalho inicia abordando o direito de acesso à justiça, previsto na Magna Carta, inclusive trazendo à baila alguns fatores que dificultam sua efetivação. Posteriormente, são abordadas algumas alternativas às políticas públicas já utilizadas para a garantia do acesso à justiça, principalmente sobre a utilização da Mediação e da Conciliação 
como possíveis mecanismos adequados para que direitos fundamentais sejam preservados.

Nesse sentido, faz-se importante verificar cada Método em separado, evidenciando quais suas características principais, suas diferenças e os motivos para que eles sejam utilizados, destacando em quais situações eles são considerados mais adequados.

Por fim, é apontada a conclusão acerca do tema em análise, sendo relevante destacar a necessidade de fomentar as políticas públicas de Mediação e Conciliação em toda a sociedade, com importante participação do Poder Judiciário, bem como de outras instituições, como o Conselho Nacional de Justiça (CNJ), para assegurar o amplo acesso a uma ordem jurídica justa.

Para tanto, a pesquisa realizou inicialmente a contextualização geral, em fontes bibliográficas sobre o tema, tanto brasileiras como estrangeiras. Esta etapa inicial de contextualização também foi realizada a partir das leis e resoluções sobre a matéria. No tocante aos Mecanismos Adequados, são consultados livros e artigos a respeito da mediação e da conciliação, como Fernanda Tartuce, William Ury, Marshall B. Rosenberg e Kazuo Watanabe. Após essa contextualização inicial, fez-se a problematização das possibilidades potenciais de utilização dos mecanismos de solução conflitual.

Ressalta-se apenas que o presente trabalho tem natureza de ensaio, não esgotando ou apresentando solução propositiva geral sobre a Mediação e a Conciliação.

\section{O DIREITO DE ACESSO À JUSTIÇA}

A Constituição Federal de 1988, também chamada de Constituição Cidadã, possui caráter humanitário, abordando direitos fundamentais e inerentes ao ser humano que antes eram negados e não reconhecidos pela sociedade. Ademais, a preocupação com a garantia dos direitos humanos passou a ser cada vez maior, sendo difundida por todo o mundo, evidenciado a sua importância e necessidade.

Entretanto, antes mesmo da Constituição Federal de 1988 (CF/88), outros ordenamentos jurídicos internacionais abordavam direitos que posteriormente seriam positivados nas leis brasileiras, como o direito ao acesso à justiça, que é vislumbrado na Declaração Universal dos Direitos Humanos, de 1948. 0 artigo $8^{\circ}$, da Declaração Universal dos Direitos Humanos, disciplina o acesso à justiça, determinando que: “Toda pessoa tem direito a receber dos tribunais nacionais competentes remédio efetivo para os atos que violem os direitos fundamentais que the sejam reconhecidos pela constituição ou lei."

Ademais, a Convenção Americana de Direitos Humanos, também chamada de Pacto de 
São José da Costa Rica, do ano de 1969, aborda o acesso à justiça em seus artigos $8^{\circ}$ e 25 , sendo que este último determina que ${ }^{1}$ :

Toda pessoa tem direito a um recurso simples e rápido ou a qualquer outro recurso efetivo, perante os juízes ou tribunais competentes, que a proteja contra atos que violem seus direitos fundamentais reconhecidos pela constituição, pela lei ou pela presente Convenção, mesmo quando tal violação seja cometida por pessoas que estejam atuando no exercício de suas funções oficiais.

Desse modo, evidencia-se que os Direitos Humanos e a preocupação com que eles sejam cumpridos são anteriores à própria Constituição Federal de 1988, encontrando respaldo em leis estrangeiras.

Dentre os direitos que estão garantidos tanto na Declaração Universal de Direitos Humanos, como no Pacto de São José da Costa Rica, bem como na Magna Carta de 1988, está o direito de acesso à justiça, positivado no artigo $5^{\circ}, \mathrm{XXXV}(\mathrm{CF} / 88)^{2}$. Segundo este artigo: “XXXV a lei não excluirá da apreciação do Poder Judiciário lesão ou ameaça a direito.”.

Outros fatores auxiliam para que o acesso à justiça seja efetivo e abranja a maior parte de pessoas, como a possibilidade de concessão de justiça gratuita, em alguns casos. Este direito está disciplinado também no artigo $5^{\circ}$, LXXIV, da CF/88, que estipula que “o Estado prestará assistência jurídica integral e gratuita aos que comprovarem insuficiência de recursos".

Ademais, outro grande incentivo para a ampliação do acesso à justiça é a criação das Defensorias Públicas por todo o território brasileiro. Tal instituição está disciplinada no artigo 134, da Magna Carta:

A Defensoria Pública é instituição permanente, essencial à função jurisdicional do Estado, incumbindo-lhe, como expressão e instrumento do regime democrático, fundamentalmente, a orientação jurídica, a promoção dos direitos humanos e a defesa, em todos os graus, judicial e extrajudicial, dos direitos individuais e coletivos, de forma integral e gratuita, aos necessitados, na forma do inciso LXXIV do art. $5^{\circ}$ desta Constituição Federal.

Assim, é evidente que a atuação das Defensorias Públicas aos hipossuficientes e aos

\footnotetext{
${ }^{1}$ BRASIL. Decreto $n^{\circ} 678$ de 6 de novembro de 1992. Promulga a Convenção Americana sobre Direitos Humanos (Pacto de São José da Costa Rica), de 22 de novembro de 1969. Diário Oficial da União, Brasília. DF. 06 de novembro de 1992. Disponível em: https://www.cidh.oas.org/basicos/portugues /C.convencao_americana.htm. Acesso em: 07 set 2017.

2 BRASIL. Constituição Federal (1988). Constituição da República Federativa do Brasil. Diário Oficial da União, Brasília. DF. 5 out. 1988. Disponível em: http://www.planalto.gov.br/ccivil_03/ constituicao/constituicaocompilado.htm. Acesso em: 28 ago. 2017.
} 
vulneráveis é imprescindível para a concretização do acesso à justiça ${ }^{3}$.

Entretanto, há alguns obstáculos a serem analisados e ultrapassados para que esse direito seja efetivo.

Entre eles, há o obstáculo no tocante ao aspecto econômico. Ainda que haja a justiça gratuita (artigo $5^{\circ}$, LXXIV, CF/88) e a atuação das Defensorias Públicas, auxiliando aqueles que não possuem recursos econômicos para arcar com os gastos processuais, a grande desigualdade econômica vivenciada no Brasil é preocupante ${ }^{4}$. 0 sistema vigente atualmente, além do fomento da globalização mundial, corroborado com corrupções nos cofres públicos, acarreta a evidente crise, que faz com que os hipossuficientes fiquem ainda mais distantes do acesso à justiça.

Várias pessoas que residem em bairros mais afastados dos centros das cidades não possuem condição econômica para se deslocarem até as Defensorias Públicas, os Fóruns, para terem orientações jurídicas, ou mesmo para irem até alguma audiência, quando designada.

Além disso, o aspecto psicológico também possui relevante influência quando abordado o tema de obstáculo ao acesso à justiça, haja vista a demora em solucionar conflitos, a insegurança da decisão final, que pode ser positiva ou negativa, e o estereótipo de "parte", "autor" e "réu", faz com que algumas pessoas sintam receio de recorrer ao Poder Judiciário, ainda que seja para pedirem o auxílio para dirimir alguma questão.

Soma-se o fato de que vários indivíduos sequer possuem o conhecimento de seus direitos. Alguns não sabem que possuem direitos básicos, como o de concessão de benefícios previdenciários, aposentadoria, medicamentos, entre outros. Porém, há outros que conhecem seus direitos, mas não sabem qual o procedimento adotado para garanti-los, evidenciando a falta de orientação jurídica.

Assim, ressalta-se a importância da aplicação do acesso à justiça de forma horizontal, alcançando todos os indivíduos, independente das diferenças existentes na sociedade, o que reflete na necessidade de políticas públicas para disseminar informações e conhecimentos acerca de direitos e deveres de todos ${ }^{5}$.

Por fim, cumpre destacar que o conceito de acesso à justiça foi ampliado e atualizado. Assim, não caracteriza apenas o acesso ao órgão judiciário, mas sim a uma ordem jurídica justa,

3 DALLEFI, Nayara Maria Silvério da Costa; FUNES; Gilmara Pesquero Fernandes Mohr. A Defensoria Pública. Disponível em: http://intertemas.unitoledo.br/revista/index.php/ETIC/article/ viewFile/1842/1748. Acesso em: 17 jun. 2017.

${ }^{4}$ FGV SOCIAL. Fundação Getúlio Vargas Social. Pobreza e desigualdade aumentaram nos últimos 4 anos no Brasil, revela estudo. Disponível em: https://cps.fgv.br/destaques/pobreza-e-desigualdadeaumentaram-nos-ultimos-4-anos-no-brasil-revela-estudo . Acesso em: 31 out. 2018.

${ }^{5}$ CAPPELETI, Mauro; GARTH, Bryant. Acesso à justiça. Tradução de Ellen Gracie Northfleet. Porto Alegre: Sérgio Antonio Fabris, 1988, p.12. 
atuando não apenas no âmbito judicial, mas também no extrajudicial. Igualmente, este é o entendimento de Kazuo Watanabe, que afirma que "os cidadãos têm o direito de ser ouvido e atendido não somente em situação de controvérsias com outrem como também em situação de problemas jurídicos que impeçam o pleno exercício da cidadania"6.

Portanto, para que haja o efetivo acesso à justiça, é necessária uma organização dos órgãos judiciários, bem como do âmbito extrajudicial, englobando também a oferta de outros serviços, como a orientação de informações e a retirada de documentos.

\subsection{Alternativas à crise do Poder Judiciário: Os Mecanismos de Solução de Conflitos}

Em decorrência do amplo acesso ao Poder Judiciário, várias são as demandas propostas pelas partes, resultando em grande aumento de processos em trâmite em todas as instâncias, sem previsão temporal de término. Corroborado a isso está o aumento da cultura do litígio, em que as partes delegam o poder de decisão a um terceiro imparcial, que é o Magistrado determinado para aquele caso concreto.

Ressalta-se que o Poder Judiciário está vivendo uma crise de processos em quantidade acima do que pode suportar, o que reflete em vários aspectos, como em audiências que são designadas em datas muito distantes daquelas em que os processos são iniciados, prejudicando algumas provas e as próprias partes, que permanecem por longo período sem saber qual será a solução final.

Sabe-se que, em média, para cada dez novas demandas propostas no Poder Judiciário, apenas três são solucionadas e, além disso, há mais de noventa e três milhões de processos que estão pendentes de resolução ${ }^{7}$.

Outros dados ${ }^{8}$ do Conselho Nacional de Justiça, de 2017 sobre o ano de 2016, mostram que na Justiça Estadual há 19.787.004 (dezenove milhões, setecentos e oitenta e sete mil e quatro) de casos novos, sendo que na Justiça Federal há 3.801.911 (três milhões, oitocentos e

\footnotetext{
${ }^{6}$ WATANABE, Kazuo. Acesso à justiça e meios consensuais de solução de conflitos. In: RODAS, João Grandino; SOUZA, Aline Anhezini de; POLONI, Juliana; SILVA, Guilherme Bertipaglia Leite da; DIAS, Eduardo Machado (Orgs). Visão Multidisciplinar das Soluções de Conflitos no Brasil. Curitiba: Prismas, 2018. p. 99.

7 CONSELHO NACIONAL DE JUSTIÇA. Manual de Mediação Judicial, 6 edição. Brasília: CNJ, 2016. Disponível em: http://www.cnj.jus.br/files/conteudo/arquivo/2016/07/ f247f5ce60df2774c59d6e2dddbfec54.pdf . Acesso em 15 de agosto de 2016, p.13.

8 CONSELHO NACIONAL DE JUSTIÇA. Justiça em números 2017: ano-base 2016. Brasília: CNJ, 2017.Disponível em: http://www.cnj.jus.br/files/conteudo/arquivo/2017/09/ 904f097f215cf19a2838166729516b79.pdf. Acesso em: 08 set. 2017, p.36.
} 
um mil, novecentos e onze) demandas novas.

Já na Justiça do Trabalho há 4.262.444 (quatro milhões, duzentos e sessenta e dois mil, quatrocentos e quarenta e quatro) de novos casos, o que significa a existência de um grande número de demandas recentes para apreciação do Poder Judiciário, sendo que grande parte desses processos não possuem prazo mínimo para serem finalizados.

O processo judicial é apenas um dos mecanismos para solucionar conflitos, sendo considerada a opção tradicional e mais comum no Brasil até o momento, porém faz-se necessário pensar em alternativas para além do Poder Judiciário. Isto corrobora com o conceito atualizado de "acesso à justiça", que prevê atuação judicial e extrajudicial, resultando em um Sistema também denominado de "Multiportas".

Há vários dispositivos no ordenamento jurídico brasileiro que dispõe acera dos novos mecanismos de resolução de conflitos, como o Novo Código de Processo Civil de $2015^{9}$, a Lei de Mediação (Lei $\left.n^{\circ} 13.140 / 15\right)^{10}$, a Resolução do Conselho Nacional de Justiça (CNJ) $n^{\circ} 125 / 10^{11}$, além das Leis $n^{\circ} 9.307 / 96^{12}$ e $13.129 / 15^{13}$, referentes à Arbitragem.

Ademais, em outros países, tais Métodos já estão sendo utilizados, como nos Estados Unidos da América (EUA), que desde a década de 1970 utilizam o sistema denominado

9 BRASIL. Lei n. 13.105, de 16 de março de 2015. Código de Processo Civil. Diário Oficial da União, Brasília, DF, 17 mar. 2015. Disponível em: http://www.planalto.gov.br/ccivil_03/_ato20152018/2015/lei/l13105.htm. Acesso em: 23 mar. 2017.

${ }^{10}$ BRASIL. Lei $n^{\circ} 13.140$ de 26 junho de 2015. Dispõe sobre a mediação entre particulares como meio de solução de controvérsias e sobre a autocomposição de conflitos no âmbito da administração pública; altera a Lei $n^{\circ} 9.469$, de 10 de julho de 1997, e o Decreto $n^{\circ} 70.235$, de 6 de março de 1972; e revoga o $\$ 2^{\circ}$ do art. $6^{\circ}$ da Lei $n^{\circ}$ 9.469, de 10 de julho de 1997. Diário Oficial da União. Brasília. DF. 26 jun. 2015. Disponível em: http://www.planalto.gov.br/ccivil_03/_ato2015-2018/2015/Lei/L13140.htm. Acesso em: 24 mar. 2017.

${ }^{11}$ CONSELHO NACIONAL DE JUSTIÇA. Resolução n. 125, de 29 de novembro de 2010. Dispõe sobre a Política Judiciária Nacional de tratamento adequado dos conflitos de interesses no âmbito do Poder Judiciário e dá outras providências. Diário da Justiça, Brasília, DF, 1 dez. 2010. Disponível em: http://www.cnj.jus.br/busca-atos-adm?documento=2579. Acesso em: 24 mar. 2017.

${ }_{12}$ BRASIL. Lei $n^{\circ} 9.307$ de 23 de setembro de 1996. Dispõe sobre a arbitragem. Diário Oficial da União, Brasília. DF. 23 set. 1996. Disponível em: <http://www.planalto.gov.br/ccivil_03/leis/L9307.htm >. Acesso em: 24 mar 2017.

${ }^{13}$ BRASIL. Lei $n^{\circ} 13.129$ de 26 de maio de 2015. Altera a Lei no 9.307, de 23 de setembro de 1996, e a Lei no 6.404, de 15 de dezembro de 1976, para ampliar o âmbito de aplicação da arbitragem e dispor sobre a escolha dos árbitros quando as partes recorrem a órgão arbitral, a interrupção da prescrição pela instituição da arbitragem, a concessão de tutelas cautelares e de urgência nos casos de arbitragem, a carta arbitral e a sentença arbitral, e revoga dispositivos da Lei № 9.307, de 23 de setembro de 1996. Diário Oficial da União, Brasília. DF. 26 mai. 2015. Disponível em: http://www.planalto.gov.br/ ccivil_03/_Ato2015-2018/2015/Lei/L13129.htm. Acesso em: 24 mar. 2017. 
"Multidoor Courthouse"14, aplicando os institutos e as devidas técnicas para a solução de controvérsias, com o consequente empoderamento das partes.

O sistema "Multidoor Courthouse", em uma tradução para o português, se refere a um Tribunal de várias portas, em que o sistema utilizado vai além da via tradicional, qual seja o Poder Judiciário, abrangendo também a Mediação, a Conciliação e a Arbitragem.

Nesse sentido, no Brasil também são utilizados tais Mecanismos, sendo que a Conciliação é utilizada há mais tempo e a Mediação é mais recente, porém, ambos ainda encontram certa resistência das partes quando aplicados para solucionar conflitos profundos e importantes, sendo um aspecto muito importante a ser desenvolvido através de políticas públicas, para a disseminação da aplicação desses institutos.

\section{POLÍTICAS PÚBLICAS DE ACESSO À JUSTIÇA}

Desde a década de 1990 os Tribunais brasileiros utilizam práticas que estimulam a autocomposição das partes. Vários são os projetos iniciais em diferentes âmbitos, sendo possível destacar alguns, como a Mediação Escolar, a Mediação Comunitária, Mediação Vítima-ofensor, Conciliação Previdenciária, entre outras.

Desse modo, com o objetivo de estabelecer novas políticas públicas que abordem a resolução adequada de conflitos e, consequentemente, o acesso à justiça, o Conselho Nacional de Justiça (CNJ) aprovou a Resolução 125/10, cujo principal escopo é o de disseminar a cultura de pacificação social, mitigando a cultura do litígio ${ }^{15}$.

A Resolução instituiu a Política Judiciária Nacional de tratamento de conflitos, assegurando que as controvérsias sejam solucionadas pelos Mecanismos, conforme a natureza e peculiaridade de cada demanda. Para tanto, foram criados os Núcleos Permanentes de Métodos Consensuais de Solução de Conflitos (NUPEMEC), com várias atribuições relacionadas à pacificação social e, consequentemente, ao acesso à justiça.

Além do NUPEMEC, foram criados os Centros Judiciários de Solução de Conflitos e Cidadania (CEJUSC), que realizam e fazem a gestão das sessões de Conciliação e Mediação, seja

14 CONSELHO NACIONAL DE JUSTIÇA. Manual de Mediação Judicial, 6 edição. Brasília: CNJ, 2016. Disponível em: http://www.cnj.jus.br/files/conteudo/arquivo/2016/07/ f247f5ce60df2774c59d6e2dddbfec54.pdf. Acesso em: 15 de agosto de 2016, p.40.

${ }^{15}$ CONSELHO NACIONAL DE JUSTIÇA. Manual de Mediação Judicial, 6 edição. Brasília: CNJ, 2016. Disponível em: http://www.cnj.jus.br/files/conteudo/arquivo/2016/07/

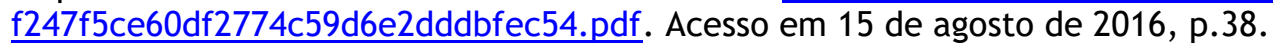


processual ou pré-processual. Ademais, atuam também na esfera da cidadania, fornecendo informações e demais orientações sobre questões jurídicas.

Nesse sentido, verifica-se que o objetivo principal é o acesso à ordem jurídica justa e eficiente, e não simplesmente ao Poder Judiciário, haja vista que o que importa não é apenas a solução de determinada demanda pelo Poder Judiciário, mas sim que os indivíduos sejam incluídos em todo o sistema de solução de $\operatorname{conflitos}^{16}$. Desse modo, não se almeja a mera coisa julgada processual, mas sim a real satisfação das partes, sendo um objetivo a ser alcançado ao utilizar os Mecanismos autocompositivos.

Após várias modificações no ordenamento jurídico, entende-se que o sistema é pluriprocessual, englobando processos auxiliares, quais sejam os heterocompositivos, como a Arbitragem, e os autocompositivos, como a Mediação e a Conciliação, que são o escopo desse trabalho.

Destaca-se que a autocomposição se difere da autotutela, também chamada de autodefesa, pois nesta o indivíduo soluciona os conflitos existentes através de sua própria força, obtendo uma vantagem em relação à parte oposta ${ }^{17}$. 0 Código Penal brasileiro atual, em seu artigo 345, proíbe a autotutela, com exceção de alguns casos, como o desforço imediato (art. 1210, \$1, Código Civil) ou de árvores limítrofes que ultrapassem o território determinado (art. 1283, Código Civil). ${ }^{18}$

Em contrapartida, a heterocomposição, definida também como heterotutela, é o mecanismo em que um terceiro imparcial determina qual a solução do conflito instaurado.

Há duas vias na modalidade heterocompositiva, sendo a primeira a via arbitral, em que se destaca como ponto positivo a especialidade do árbitro para resolução de determinada questão, além disso, sua decisão possui força vinculativa entre as partes, configurando como título executivo. A segunda via é a jurisdicional, em que o magistrado é o terceiro imparcial e o poder coercitivo é constante. Nessa segunda opção quem irá decidir o resultado da demanda é uma pessoa imparcial que seguirá os tramites impostos e elencados pelas legislações brasileiras positivadas.

Assim, o acesso à justiça, direito fundamental garantido pela Constituição Federal de

${ }^{16}$ CONSELHO NACIONAL DE JUSTIÇA. Manual de Mediação Judicial, 6 edição. Brasília: CNJ, 2016. Disponível em: http://www.cnj.jus.br/files/conteudo/arquivo/2016/07/ f247f5ce60df2774c59d6e2dddbfec54.pdf. Acesso em 15 de agosto de 2016, p.39.

${ }^{17}$ TARTUCE, Fernanda. Mediação nos conflitos civis. São Paulo: Método. 2016 p. 19.

18 ÁLVARES, Rodrigo Feracini. Solução extrajudicial e direito fundamental de acesso à justiça. Dissertação (Mestrado) - Faculdade de Direito / Programa de Pós- Graduação em Direito - Universidade Metodista de Piracicaba. Piracicaba, SP: [s.n.], 2014. 117 f, p. 16. 
1988, não deve apenas ser efetivo, mas também deve ser adequado, tempestivo e justo, observando não apenas a questão controvertida, mas todos os seus envolvidos. Nesse sentido, cita-se importante trecho do Manual de Mediação Judicial, do Conselho Nacional de Justiça $(\mathrm{CNJ})^{19}$ :

Inicialmente o movimento de acesso à justiça buscava endereçar conflitos que ficavam sem solução em razão da falta de instrumentos processuais efetivos ou custos elevados, voltando-se a reduzir a denominada litigiosidade contida. Contudo, atualmente, a administração da justiça volta-se a melhor resolver disputas afastando-se muitas vezes de fórmulas exclusivamente positivadas e incorporando métodos interdisciplinares a fim de atender não apenas aqueles interesses juridicamente tutelados mas também outros que possam auxiliar na sua função de pacificação social.

Portanto, percebe-se que há uma importante inovação quanto ao acesso à justiça. Este passa a ser caracterizado pela busca efetiva de solução para as controvérsias dos indivíduos, que resulta na harmonia social, no empoderamento das partes e na consciência de que em determinadas causas elas mesmas serão os melhores autores das decisões.

Nesse contexto, novas políticas públicas devem ser criadas para implementação de determinados mecanismos, alguns já utilizados pelos próprios Tribunais, e outros a serem criados e aperfeiçoados. Assim, faz-se necessário o estudo mais aprofundado sobre a Mediação e a Conciliação, analisando tais Mecanismos como possibilidades para efetivar o acesso à justiça.

\subsection{Mediação}

A Mediação é instituto previsto em vários dispositivos da legislação brasileira, como o Código de Processo Civil de 2015, a Resolução n 125/10, do CNJ e a Lei n 13.140/15.

Primeiramente, a Mediação é mecanismo autocompositivo de resolução de conflitos, em que um terceiro imparcial chamado de Mediador, é convocado para auxiliar e facilitar o diálogo entre as partes, com o objetivo de empoderá-las para que elas mesmas tenham a consciência de que são capazes de solucionarem seus conflitos.

19 CONSELHO NACIONAL DE JUSTIÇA. Manual de Mediação Judicial, 6 edição. Brasília: CNJ, 2016. Disponível em: <http://www.cnj.jus.br/files/conteudo/arquivo/2016/07/f247f5ce60df2774c59d6e2dddbfec54.pdf>. Acesso em 15 de agosto de 2016, p.40. 
Segundo Tartuce ${ }^{20}$ :

Mediação é o meio consensual de abordagem de controvérsias em que uma pessoa isenta e devidamente capacitada atua tecnicamente para facilitar a comunicação entre as pessoas para propiciar que elas possam, a partir da restauração do diálogo, encontrar formas proveitosas de lidar com as disputas.

Analisando este Mecanismo historicamente, constata-se a sua evolução nos Estados Unidos da América, principalmente a partir do ano de 1970. Paralelamente, ocorreu o desenvolvimento deste Método em outros países, como na Austrália, no Reino Unido e Canadá. ${ }^{21}$

Nesse sentido, Briquet afirma sobre o desenvolvimento da Mediação e as duas direções em que ela é compreendida ${ }^{22}$ :

Uma corrente baseada na noção de que a mediação é uma extensão do sistema jurídico. Em vista desta situação, muitos juízes e advogados ainda veem a mediação tão somente como um meio eficaz de reduzir problemas de litígio nos tribunais. A outra direção é a desassociada do sistema jurídico e concebe a mediação como um processo que poderia produzir melhores resultados daqueles do sistema contraditório apenas por ser separada da burocracia legal. (...) Uma outra vertente acredita que o principal valor da mediação está em encorajar as partes a exercitar sua autonomia, suas escolhas e a autodeterminação. Esta última parece ser a maior tendência mundial.

Assim, percebe-se que desde os primórdios da aplicação deste Mecanismo para solucionar conflitos, há indivíduos que entendem que a Mediação é uma solução adequada para determinados conflitos.

A Mediação é comumente aplicada em causas que as partes já possuem prévio relacionamento, antes mesmo desse acontecimento que gerou o conflito, sendo que o relacionamento e a convivência entre eles permanecerão também depois da resolução daquele.

0 artigo 694, do Código de Processo Civil de 2015, disciplina que nas ações de família, todos os esforços serão utilizados para que a audiência de Mediação ocorra, lembrando que deve haver uma equipe multidisciplinar para auxiliar o procedimento da audiência.

Não apenas para ações de família o instituto da Mediação pode ser utilizado. Há várias aplicações desse mecanismo, como por exemplo, a Mediação escolar, que está sendo utilizada cada vez mais nas escolas brasileiras.

Brevemente explicando, a Mediação escolar consiste no trabalho exercido pelo Mediador,

\footnotetext{
${ }^{20}$ TARTUCE, Fernanda. Mediação nos conflitos civis. São Paulo: Método. 2016, p.52.

${ }^{21}$ BRIQUET, Enia Cecilia. Manual de Mediação: teoria e prática na formação do mediador. Petrópolis, Rio de Janeiro: Vozes, 2016, p. 130.

22 BRIQUET, Enia Cecilia. Manual de Mediação: teoria e prática na formação do mediador. Petrópolis, Rio de Janeiro: Vozes, 2016, p. 130.
} 
em parceria com demais profissionais de outras áreas, como psicólogos, assistentes sociais, funcionários das escolas nas quais a Mediação é aplicada, além e, principalmente, dos alunos, parte imprescindível do processo de Mediação ${ }^{23}$.

Destaca-se, portanto, que o instituto da Mediação é utilizado em várias áreas, haja vista que objetiva a promoção da cultura de pacificação e do diálogo, pois entende que as próprias partes são capazes de resolver seus litígios, sendo que o Poder Judiciário deve ficar responsável apenas pelas demandas que não são possíveis de solução através do diálogo, ou que provas importantes são difíceis de serem constituídas ou preservadas.

\subsection{0 papel do Mediador para efetivação das políticas públicas}

O Mediador é pessoa capacitada para aplicação da Mediação. Através das técnicas específicas, faz-se a neutralização das questões trazidas pelas partes, trabalhando a empatia, que é a capacidade de se colocar no lugar dos outros além de reforçar e aplicar a escuta ativa, para que as partes entendam que não devem apenas escutar o que o outro está falando, mas ouvir interpretando, com atenção, para absorver tudo o que o indivíduo está expressando.

Há princípios que regem a Mediação, sendo comuns também à Conciliação, como os Princípios da Autonomia da Vontade das Partes, que destaca que as partes apenas realizam o acordo caso se sintam confortáveis e favoráveis às opções compactuadas. Além disso, o Princípio da Informalidade é inerente à sessão de Mediação, prezando pela oralidade dos presentes, que relatam os fatos e as questões controvertidas.

Ainda no tocante aos Princípios, a imparcialidade do Mediador deve ser constante e nítida, de modo que as partes se sintam confortáveis em conversar suas controvérsias naquele ambiente e com aquelas pessoas ali presentes, assim, não é autorizado qualquer favoritismo ou preferência ${ }^{24}$. Por fim, o Princípio da Confidencialidade é importantíssimo para uma excelente Mediação, corroborando com a finalidade de fazer com que os participantes sintam-se seguros em dialogar.

${ }^{23}$ MORGADO, Catarina; OLIVEIRA, Isabel. Mediação em contexto escolar: transformar o conflito em oportunidade. Exedra, Coimbra. $\mathrm{n}^{\circ}$ 1, p. 46 - 56, jun. 2009. Disponível em: $<$ https: / / dialnet.unirioja.es/servlet/articulo?codigo=3398314> . Acesso em: 28 ago 2017.

${ }^{24}$ RODRIGUES, Edwirges Elaine; ALVARENGA, Maria Amália de Figueiredo Pereira. A política pública de mediação como instrumento de busca do consenso parental e seus reflexos na efetivação da guarda compartilhada. Revista Eletrônica do Curso de Direito da UFSM, Santa Maria, RS, v. 13, n. 2, p. 532-553, ago. 2018. ISSN 1981-3694. Disponível em: https://periodicos.ufsm.br/revistadireito/article/view/28787 . Acesso em: 28, out, 2018. doi: http://dx.doi.org/10.5902/1981369428787. 
Ademais, outras técnicas são utilizadas pelo Mediador, como a comunicação não-violenta (CNV). Rosenberg ${ }^{25}$ afirma sobre o tema:

[..] identifiquei uma abordagem específica da comunicação - falar e ouvir - que nos leva a nos entregarmos de coração, ligando-nos a nós mesmos e aos outros de maneira tal que permite que nossa compaixão natural floresça. Denomino essa abordagem como Comunicação Não-Violenta, usando o termo "não-violência" na mesma acepção que the atribuía Gandhi - referindo-se a nosso estado compassivo natural quando a violência houver se afastado do coração.

Assim, em consequência, a essência das técnicas é transmitida para as partes ali presentes, refletindo nas relações dessas pessoas com terceiros que não estão envolvidos na controvérsia.

Nesse sentido, percebe-se a importância de uma boa formação do Mediador, para que ele saiba aplicar todas as técnicas aprendidas. Assim, é notória a necessidade de cursos para formação de Mediador conforme os ditames do Conselho Nacional de Justiça, que na Resolução 125/10 exige tanto a parte teórica do curso, como também a parte prática, supervisionada por profissional capacitado.

Apenas um Mediador corretamente formado e treinado para a aplicação das técnicas definidas é que pode exercer corretamente a política pública de aplicação dos mecanismos adequados de resolução de conflitos, transmitindo para as partes o real significado da Mediação, fazendo com que elas entendam que ninguém melhor do que elas próprias para solucionarem alguns conflitos ${ }^{26}$.

\subsection{Conciliação}

A Conciliação é outro mecanismo de resolução de conflitos que é alternativo ao processo judiciário tradicional e também é autocompositivos, assim como a Mediação.

Em contraposição à Mediação, a Conciliação é utilizada para casos em que as partes não se conhecem previamente. Desse modo, entende-se que é um instituto aplicado para solucionar questões específicas, como acidentes de carro, em que as partes se relacionam apenas naquele momento, podendo nunca se encontrar após a solução da controvérsia.

Ainda que a Conciliação seja um instituto com algumas diferenças em relação à

\footnotetext{
${ }^{25}$ ROSENBERG, Marshall B. Comunicação não-violenta: Técnicas para aprimorar relacionamentos pessoais e profissionais. São Paulo: Ágora. 2006, p.21.

${ }^{26}$ URY, Willian L. Supere o Não: Negociando com pessoas difíceis. Trad. Regina Amarante. São Paulo: Best Seller. 2003.
} 
Mediação, é notório que ambos lidam com o conflito da mesma forma: entendendo que é algo positivo, e que, quando bem trabalhado, pode gerar excelentes frutos e reflexos para toda a sociedade.

Conforme abordado anteriormente, os indivíduos se relacionam e trocam experiências constantemente, desse modo, é natural que surjam conflitos e que questões controvertidas façam parte do cotidiano da sociedade. Assim, é importante a participação das partes, e não apenas do Estado, na construção de soluções para as controvérsias que ocasionalmente surjam no contexto social.

\subsection{O Conciliador e sua atuação nas políticas públicas de Mecanismos consensuais}

Assim como existem diferenças entre a Mediação e a Conciliação, é notório que também existem diferenças quanto ao papel do Mediador e do Conciliador.

No tocante ao Conciliador, faz-se necessário destacar que, ao contrário do Mediador, ele pode sugerir algumas alternativas para solucionar as questões trazidas. Assim, além de facilitar o diálogo, ele aplica algumas técnicas, como a empatia, a escuta ativa, a normalização e a solidariedade, para que as partes se sintam confortáveis em pensar de modo criativo em novas soluções e também para refletirem sobre as sugestões apontadas pelo Conciliador.

Tendo em vista que a Mediação e a Conciliação são institutos autocompositivos, em que pretendem uma real mudança de cultura em toda a sociedade, é imprescindível que a intenção do ganho mútuo esteja presente nas audiências, para que as partes possam transmitir os ensinamentos e as práticas para além dos Fóruns e das câmaras privadas, disseminando as técnicas e aplicando em suas vidas pessoais.

Nesse sentido, Ury afirma que ${ }^{27}$ :

Receamos que, se colaborarmos, não haverá o suficiente para atender às nossas necessidades ou seremos explorados pelo outro lado. É bastante tentador nos concentrarmos apenas na conquista de resultados para nós mesmos em vez de na criação de valor para os outros e para nós. No entanto, por mais difíceis que as pessoas às vezes sejam, a oportunidade de mudar o jogo para ganha-ganha-ganha está em nossas mãos.

Assim, é notório que a mudança começa no interior em cada indivíduo, para que ele perceba a importância que é se empoderar e ter nas suas escolhas e no diálogo o instrumento

${ }^{27}$ URY, Willian L. Como chegar ao SIM com você mesmo. Trad. Afonso Celso da Cunha. Rio de Janeiro: Sextante, 2015, p.110. 
essencial para resolver todas as controvérsias que surjam. Porém, sem nunca esquecer que o Poder Judiciário sempre está disposto a recepcionar e a solucionar os conflitos que não sejam passíveis de conciliar ou de mediar.

\section{CONCLUSÃO}

0 direito de acesso à justiça ( $\mathrm{CF} / 88$, art. $\left.5^{\circ}, \mathrm{XXXV}\right)$ é extenso e abrange tanto o âmbito judicial, quanto o extrajudicial, assim, o Poder Judiciário não é a única via utilizada para que a sociedade assegure seus direitos. Nesse sentido, os mecanismos de resolução de conflitos, especialmente a Mediação e a Conciliação, passam a ter funções importantes e colaboram com a redução da cultura de litígio e implantação da cultura de pacificação e de empoderamento das partes.

Após o exposto, é possível concluir que ainda há necessidade de ampliar as políticas públicas para o acesso à justiça, não apenas no tocante a via tradicional, qual seja a do Poder Público, mas também a via extrajudicial, em que atuam a Mediação e a Conciliação.

Assim, é necessária a consolidação de políticas públicas para incentivar e contribuir com a prática desses Mecanismos consensuais, atuando em três principais âmbitos: na formação e capacitação dos Mediadores e Conciliadores; na disseminação dessa nova cultura por toda a sociedade, informando a existência de uma via diferente do Poder Judiciário, oferecendo condições para que os indivíduos, em alcance horizontal, tenham acesso às informações e aos Mecanismos; e que os advogados também orientem seus clientes sobre a possibilidade de Mediação e de Conciliação, estando devidamente capacitados para atuar nestas sessões.

O fortalecimento de ações como a Semana Nacional da Conciliação, realizada anualmente pelo Conselho Nacional de Justiça, as Oficinas de Parentalidade, que ocorrem nos Tribunais em todo território brasileiro, além da atuação dos NUPEMECs e CEJUSCs, são essenciais para a consecução do acesso à justiça.

Por fim, é necessário destacar a importância das políticas públicas para a efetivação dos Métodos adequados de resolução de conflitos, principalmente a Mediação e a Conciliação, para auxiliar na garantia e no cumprimento do direito de acesso à justiça em ampla escala, justo e adequado, sendo que é imprescindível que as partes tenham consciência de que elas possuem a capacidade de dialogar e solucionar seus conflitos, sendo que o Poder Judiciário auxiliará apenas 
nas demandas em que a aplicação dos Mecanismos consensuais não for a mais adequada.

\section{REFERÊNCIAS}

ÁLVARES, Rodrigo Feracini. Solução extrajudicial e direito fundamental de acesso à justiça. Dissertação (Mestrado) - Faculdade de Direito / Programa de Pós- Graduação em Direito Universidade Metodista de Piracicaba. Piracicaba, SP: [s.n.], 2014. 117 f.

BRASIL. Constituição Federal (1988). Constituição da República Federativa do Brasil. Diário Oficial da União. Brasília. DF. 5 out. 1988. Disponível em: http://www.planalto.gov.br/ccivil_03/constituicao/constituicaocompilado.htm. Acesso em: 28 ago. 2017.

BRASIL. Decreto $n^{\circ} 678$ de 6 de novembro de 1992. Promulga a Convenção Americana sobre Direitos Humanos (Pacto de São José da Costa Rica), de 22 de novembro de 1969. Diário Oficial da União, Brasília. DF. 06 de novembro de 1992. Disponível em: https://www.cidh.oas.org/basicos/portugues/c.convencao_americana.htm. Acesso em: 07 set. 2017.

BRASIL. Lei n. 13.105, de 16 de março de 2015. Código de Processo Civil. Diário Oficial da União, Brasília, DF, 17 mar. 2015. Disponível em: http://www.planalto.gov.br/ccivil_03/_ato2015-2018/2015/lei/l13105.htm. Acesso em: 23 mar. 2017.

BRASIL. Lei $n^{\circ} 13.129$ de 26 de maio de 2015. Altera a Lei $n^{\circ}$ 9.307, de 23 de setembro de 1996, e a Lei $n^{\circ}$ 6.404, de 15 de dezembro de 1976, para ampliar o âmbito de aplicação da arbitragem e dispor sobre a escolha dos árbitros quando as partes recorrem a órgão arbitral, a interrupção da prescrição pela instituição da arbitragem, a concessão de tutelas cautelares e de urgência nos casos de arbitragem, a carta arbitral e a sentença arbitral, e revoga dispositivos da Lei no 9.307, de 23 de setembro de 1996. Diário Oficial da União, Brasília. DF. 26 mai. 2015. Disponível em: http://www.planalto.gov.br/ccivil_03/_Ato2015-2018/2015/Lei/L13129.htm. Acesso em: 24 mar. 2017.

BRASIL. Lei $n^{\circ} 13.140$ de 26 junho de 2015. Dispõe sobre a mediação entre particulares como meio de solução de controvérsias e sobre a autocomposição de conflitos no âmbito da administração pública; altera a Lei $\mathrm{n}^{\circ} 9.469$, de 10 de julho de 1997, e o Decreto $\mathrm{n}^{\circ} 70.235$, de 6 de março de 1972; e revoga o $\$ 2^{\circ}$ do art. $6^{\circ}$ da Lei $n^{\circ} 9.469$, de 10 de julho de 1997. Diário Oficial da União, Brasília. DF. 26 jun. 2015. Disponível em: http://www.planalto.gov.br/ccivil_03/_ato2015-2018/2015/Lei/L13140.htm. Acesso em: 24 mar. 2017.

BRASIL. Lei $\mathrm{n}^{\circ} 9.307$ de 23 de setembro de 1996. Dispõe sobre a arbitragem. Diário Oficial da União, Brasília. 23 set. 1996. Disponível em: http://www.planalto.gov.br/ccivil_03/leis/L9307.htm . Acesso em: 24 mar. 2017.

BRIQUET, Enia Cecilia. Manual de Mediação: teoria e prática na formação do mediador. Petrópolis, Rio de Janeiro: Vozes, 2016. 
CAPPELETI, Mauro; GARTH, Bryant. Acesso à justiça. Tradução de Ellen Gracie Northfleet. Porto Alegre: Sérgio Antonio Fabris, 1988.

CONSELHO NACIONAL DE JUSTIÇA. Justiça em números 2017: ano-base 2016. Brasília: CNJ, 2017.Disponível

em: http://www.cnj.jus.br/files/conteudo/arquivo/2017/09/904f097f215cf19a2838166729516b79.pd f. Acesso em: 08 set. 2017.

CONSELHO NACIONAL DE JUSTIÇA. Manual de Mediação Judicial, 6 edição. Brasília: CNJ, 2016. Disponível em: http://www.cnj.jus.br/files/conteudo/arquivo/2016/07/f247f5ce60df2774c559d6e2dddbfec54.p df. Acesso em 15 de agosto de 2016.

CONSELHO NACIONAL DE JUSTIÇA. Resolução n. 125, de 29 de novembro de 2010. Dispõe sobre a Política Judiciária Nacional de tratamento adequado dos conflitos de interesses no âmbito do Poder Judiciário e dá outras providências. Diário da Justiça, Brasília, DF, 1 dez. 2010. Disponível em: http://www.cnj.jus.br/busca-atos-adm?documento=2579. Acesso em: 24 mar. 2017.

DALLEFI, Nayara Maria Silvério da Costa; FUNES, Gilmara Pesquero Fernandes Mohr. A Defensoria Pública. Disponível em: http://intertemas.unitoledo.br/revista/index.php/ETIC/article/viewFile/1842/1748. Acesso em: 17 jun. 2017.

FGV SOCIAL. Fundação Getúlio Vargas Social. Pobreza e desigualdade aumentaram nos últimos 4 anos no Brasil, revela estudo. Disponível em: https://cps.fgv.br/destaques/pobreza-edesigualdade-aumentaram-nos-ultimos-4-anos-no-brasil-revela-estudo. Acesso em: 31 out. 2018.

MORGADO, Catarina; OLIVEIRA, Isabel. Mediação em contexto escolar: transformar o conflito em oportunidade. Exedra, Coimbra. $\mathrm{n}^{\circ} 1$, p. 46 - 56, jun. 2009. Disponível em: https://dialnet.unirioja.es/servlet/articulo?codigo=3398314. Acesso em: 28 ago. 2017.

RODRIGUES, Edwirges Elaine; ALVARENGA, Maria Amália de Figueiredo Pereira. A política pública de mediação como instrumento de busca do consenso parental e seus reflexos na efetivação da guarda compartilhada. Revista Eletrônica do Curso de Direito da UFSM, Santa Maria, RS, v. 13, n. 2, p. 532-553, ago. 2018. ISSN 1981-3694. Disponível em: https://periodicos.ufsm.br/revistadireito/article/view/28787. Acesso em: 28 out. 2018. doi:http://dx.doi.org/10.5902/1981369428787.

ROSENBERG, Marshall B. Comunicação não-violenta: Técnicas para aprimorar relacionamentos pessoais e profissionais. São Paulo: Ágora. 2006.

TARTUCE, Fernanda. Mediação nos conflitos civis. São Paulo: Método. 2016.

URY, Willian L. Como chegar ao SIM com você mesmo. Trad. Afonso Celso da Cunha. Rio de Janeiro: Sextante, 2015.

URY, Willian L. Supere o Não: Negociando com pessoas difíceis. Trad. Regina Amarante. São Paulo: Best Seller. 2003. 
WATANABE, Kazuo. Acesso à justiça e meios consensuais de solução de conflitos. In: RODAS, João Grandino; SOUZA, Aline Anhezini de; POLONI, Juliana; SILVA, Guilherme Bertipaglia Leite da; DIAS, Eduardo Machado (Orgs). Visão Multidisciplinar das Soluções de Conflitos no Brasil. Curitiba: Prismas, 2018.

Recebido em: 30.11.2017 / Revisões requeridas em: 21.10.2018 / Aprovado em: 26.12.2018 / Publicado em: 28.02.2019

\section{COMO FAZER REFERÊNCIA AO ARTIGO (ABNT):}

BORGES, Alexandre Walmott; MENEGAZ, Mariana Lima. Mecanismos adequados de solução de conflitos como políticas públicas para a efetivação do acesso à Justiça. Revista Eletrônica do Curso de Direito da UFSM, Santa Maria, RS, v. 14, n. 1, e30187, jan./abr. 2019. ISSN 1981-3694. Disponível em:

https://periodicos.ufsm.br/revistadireito/article/view/30187 Acesso em: dia mês. ano. doi: http://dx.doi.org/10.5902/1981369430187.

Direitos autorais 2019 Revista Eletrônica do Curso de Direito da UFSM

Editores responsáveis: Rafael Santos de Oliveira e Angela Araujo da Silveira Espindola

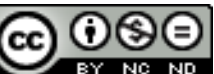

Este obra está licenciado com uma Licença Creative Commons Atribuição-NãoComercial-SemDerivações 4.0 Internacional.

\section{SOBRE OS AUTORES}

\section{ALEXANDRE WALMOTT BORGES}

É graduado em Direito pela Universidade Federal de Santa Catarina (1994), Especialista em História e Filosofia da ciência, mestre em Direito pela Universidade Federal de Santa Catarina (1996) e doutor em Direito pela Universidade Federal de Santa Catarina (2002). Doutor em História pela Universidade Federal de Uberlândia UFU (2019). Atualmente é professor dos programas de pós graduação, mestrado em direito, da Universidade Federal de Uberlândia - UFU, e da Universidade Estadual Paulista Júlio de Mesquita Filho - UNESP; é professor da pós-graduação em biocombustíveis, mestrado e doutorado, programa conjunto da Universidade Federal de Uberlândia e Universidade Federal dos Vales do Mucuri e Jequitinhonha. Tem experiência na área de Direito, com ênfase em Direito Constitucional e na Ordem Econômica Constitucional, com interesses de pesquisa principalmente nos seguintes temas: história e teoria constitucional (sistemas jurídicos constitucionais em comparação, laicidade e associação religiosa do estado, história constitucional brasileira, história dos sistemas de controle de constitucionalidade, história da ordem econômica constitucional); direito constitucional econômico (política normativa da economia, sistemas normativos da energia, estado, serviços públicos e atividades econômicas estatais). É pesquisador líder do Laboratório Americano de Estudos Constitucionais Comparados - LAECC. Orienta projetos de iniciação científica, dissertações e teses pela FAPEMIG e CNPQ. Realiza projetos com financiamento da FAPEMIG e da CAPES. Realizou estágio de pós-doutorado na Universidade Autônoma de Barcelona sob a supervisão do Professor Doutor José Carlos Remotti Carbonell, com pesquisa na área de constitucionalismo multinível. Realizou estágio de pesquisador visitante na Universidade de Barcelona, Faculdade de Filosofia, com a associação à pesquisa Capitalismo e Temporalidade sob a coordenação do Professor Gonçal Mayos.

\section{MARIANA LIMA MENEGAZ}

Mariana Lima Menegaz é mestranda em Direito na Universidade Estadual Paulista " Júlio de Mesquita Filho" (UNESP - Franca/SP). Advogada, pós-graduada em Direito Processual Civil e Argumentaqção Jurídica pela PUCMinas (2016-2018), graduada pela Faculdade de Direito de Franca - SP (12/2015) e aprovada no XVI Exame de 
ISSN 1981-3694

(DOI): $10.5902 / 1981369430187$

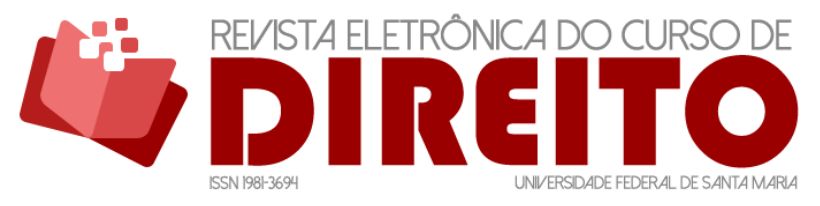

MECANISMOS ADEQUADOS DE SOLUÇÃO DE CONFLITOS COMO POLITICA PÚBLICA PARA A EFETIVAÇÃ̃O DO ACESSO À JUSTIÇA

ALEXANDRE WALMOTT BORGES MARIANA LIMA MENEGAZ

Ordem da OAB em Junho/2015. Membro da Comissão de Mediação e Conciliação da OAB - Uberlândia/MG. Membro do Grupo de Pesquisa "As Novas Vertentes dos Direitos da Personalidade" (dgp.cnpq.br/dgp/espelhogrupo/7173037051746636). Membro do Núcleo de Aperfeiçoamento em Ciências Criminais da Faculdade de Franca - NACCRIM (2013). Membro do Núcleo de Estudos Constitucionais da Faculdade de Franca (2011). Estágio voluntário no Ministério Público Estadual de Franca (2012 -2013). Estágio no Juizado Especial Federal de Franca - SP (2013-2015). Estágio supervisionado de Mediação e Conciliação no CEJUSC/ TJ - DFT. Brasília, DF. Ênfase nas áreas de Mediação, Conciliação e Arbitragem, Direitos Humanos e Ciências Criminais. Interesse de pesquisa principalmente nos seguintes temas: Mediação, Conciliação, Arbitragem, Direito Constitucional, História dos Direitos Sociais, Direitos Humanos, Administração Pública. 